\title{
Australian climate change policy - where to from here?
}

Over the past decade, Australia's approach to climate change policy could be described as erratic. In 2007, both major political parties announced support for a domestic emissions trading scheme (ETS) but bipartisan agreement evaporated in 2009. An ETS was established in 2011 but then repealed in 2014. The Commonwealth Government has subsequently introduced a 'Direct Action' climate change policy but there is little political agreement about the best long-term policy approach. This is unfortunate given climate science is indicating that relatively significant cuts to emissions may be required to avoid 'dangerous climate change'. This article provides some insights for future Australian climate change policy suggested by an analysis of the realities of electricity generation costs, international policy settings and Australian policy history. Enlightened and effective policy cannot ignore how comparative generation costs affect incentives to replace existing assets and how different policy instruments impact on electricity prices. As a significant exporter of emitting fuels, Australia would also be wise to consider how to manage the economic risks of reduced international demand for these fuels in the absence of technological development that eliminates externality costs. Such consideration could be focused on both reductions in domestic emissions and Australia's strategic negotiating position ahead of international climate change mitigation negotiations in late 2015.

Keywords: climate-change; emissions trading; energy

JEL Codes: D04, D47, Q40, Q41, Q48

\section{Introduction}

In late 2014, the Intergovernmental Panel on Climate Change (IPCC) released its Fifth Assessment Report (AR5) summarising the scientific consensus on aspects of climate change (IPCC, 2014). Globally, significant reductions in anthropogenic greenhouse gas (GHG) emissions are recommended to limit atmospheric concentrations of GHG to $450 \mathrm{ppm}$. The IPCC states that such an achievement would be likely to limit global warming to less than $2^{0} \mathrm{C}$ above pre-industrial levels. This has important, but ambiguous implications for the Australian energy sector. Limiting emissions will require individual sovereign nations to cooperate to reduce emissions, agree on appropriate individual national contributions to reduce emissions and invest in new forms of energy production. Such an outcome will be politically challenging, as Australia's own difficulties in deciding on the best policy to reduce emissions exemplifies.

At the APEC summit in late 2014, China and the US agreed to non-legally binding reductions in emissions. China committed to cap its GHG emissions by 2030 and to increase the share of nonfossil energy sources to $20 \%$ by 2030 . The US agreed to reduce GHG emissions by 26 to $28 \%$ below 2005 levels by 2025 (ABC, 2014). Such an agreement is likely to have important ramifications for Australia as China and the US are the two largest emitters in the world with annual GHG emissions of around 10 gigatonnes (Gt) and $5 \mathrm{Gt}$ respectively from fossil fuel use and cement production (European Commission, 2013). Collectively, these nations emit $42 \%$ of global emissions associated with fossil fuel consumption and major industrial processes (EPA, 2014). 
In December 2015, the United Nations Framework Convention on Climate Change (UNFCCC) Conference of the Parties (COP) will meet in Paris. The China/US agreement is likely to spur further global negotiations around an agreement to limit GHG emissions, possibly through a legally binding global treaty. Irrespective of whether such negotiations produce an outcome that would require Australia to constrain emissions, it is important that Australian climate change policy adequately address the economic risks associated with global policies beyond Australia's influence.

Australia currently has two main climate change policy mechanisms. The first is a 'Direct Action' policy which involves the Commonwealth Government operating a reverse auction process to allocate $\$ 2.5$ billion to fund emission reduction projects. The policy also incorporates 'baselines' for individual emitting facilities operating within Australia although it is unclear at the time of writing how this policy is to be implemented. The second policy is the $20 \%$ Renewable Energy Target (RET) which requires electricity retailers to fund small-scale solar PV systems and increase the proportion of large-scale renewables in the overall electricity mix. Much of the focus in relation to Australian emissions is on the domestic electricity sector. While this sector should not be overlooked, it could be argued that Australia's policy initiatives should also be focused on the strategic importance of our resources - primarily coal, gas and uranium. BREE (2012a, p. 1) estimates that Australia has 33\%, 10\% and 2\% respectively of the world's uranium, coal and gas resources. In the year to November 2014, 26\% of Australia's goods export revenues were sourced from the sale of coal and other mineral fuels (ABS, 2014). This is likely to grow as the $\$ 60$ billion CSG to LNG industry commences production in 2015/16 in Queensland. Given the strategic importance of coal, uranium and gas exports for the Australian economy, greater consideration of appropriate and cost-effective policy mechanisms for these resource industries would appear sensible.

This paper assesses the latest climate science and potential implications for an Australian 'GHG budget'; and provides climate policy insights based upon lessons learned through recent Australian and international experience. The paper is structured as follows: Section 2 provides a summary of climate science and its implications for Australian GHG emissions; a brief overview of Australian and international climate change policy is discussed in Section 3; the lessons learned through these policy experiences and subsequent insights for Australian policy reform are proposed in Section 4; with concluding remarks provided in Section 5.

\section{Implications of climate science for Australian emissions of GHG}

In 1850, annual anthropogenic global carbon dioxide emissions were around 2 gigatonnes (Gt). Since that time there has been a steady growth in emissions associated with global industrialisation. In 2013, global carbon dioxide emissions were approximately 37 Gt. Including other GHG, global anthropogenic emissions are around $50 \mathrm{Gt}$ each year. This increase in emissions has resulted in a significant rise in the concentration of GHG emissions in the atmosphere from approximately 280 parts per million (ppm) in 1850 to nearly 400 ppm today the highest level in at least 800,000 years. The IPCC has stated that this is, '..extremely likely to have been the dominant cause of the observed warming since the mid- $20^{\text {th }}$ century' (IPCC, 2014, p. 5). Between the late 1800s and today, average combined land and ocean surface temperatures increased by $0.85^{\circ} \mathrm{C}$. To summarise simply, 'human influence on the climate system is clear' (IPCC, 2014, p. 3). 
The IPCC has estimated that in the absence of GHG mitigation policies, global mean surface temperatures are likely to be between $2.5^{\circ} \mathrm{C}$ and $7.8^{0} \mathrm{C}$ greater than pre-industrial levels by 2100 . To limit temperature increases to less than $2^{0} \mathrm{C}$, it is likely that concentrations of GHG in the atmosphere need to be limited to $450 \mathrm{ppm}$ or lower. Such a limit would require reductions in global anthropogenic emissions of between $40 \%$ and $70 \%$ by 2050 and complete decarbonisation of the world economy by 2100. It is extremely difficult to envisage how a global limitation on GHG emissions would be distributed among individual sovereign nations. There are many ways in which emission reduction obligations could be calculated based upon historical emissions, population, GDP and other variables. A range of methodologies and associated 'carbon budgets' (the total GHG emissions permitted between 2015 and 2050) is presented in Figure 1. The scenarios presented were developed by The Climate Institute and utilise well-understood distribution frameworks such as 'contraction and convergence'. Further information on these scenarios can be sourced from TCI (2014) but for the purposes of this article, it is important to note that even under even the most 'generous' of distribution methods, Australian emissions between 2015 and 2050 would need to be capped at around $10 \mathrm{Gt}$.

Figure 1: Australian carbon budgets under different distributional scenarios

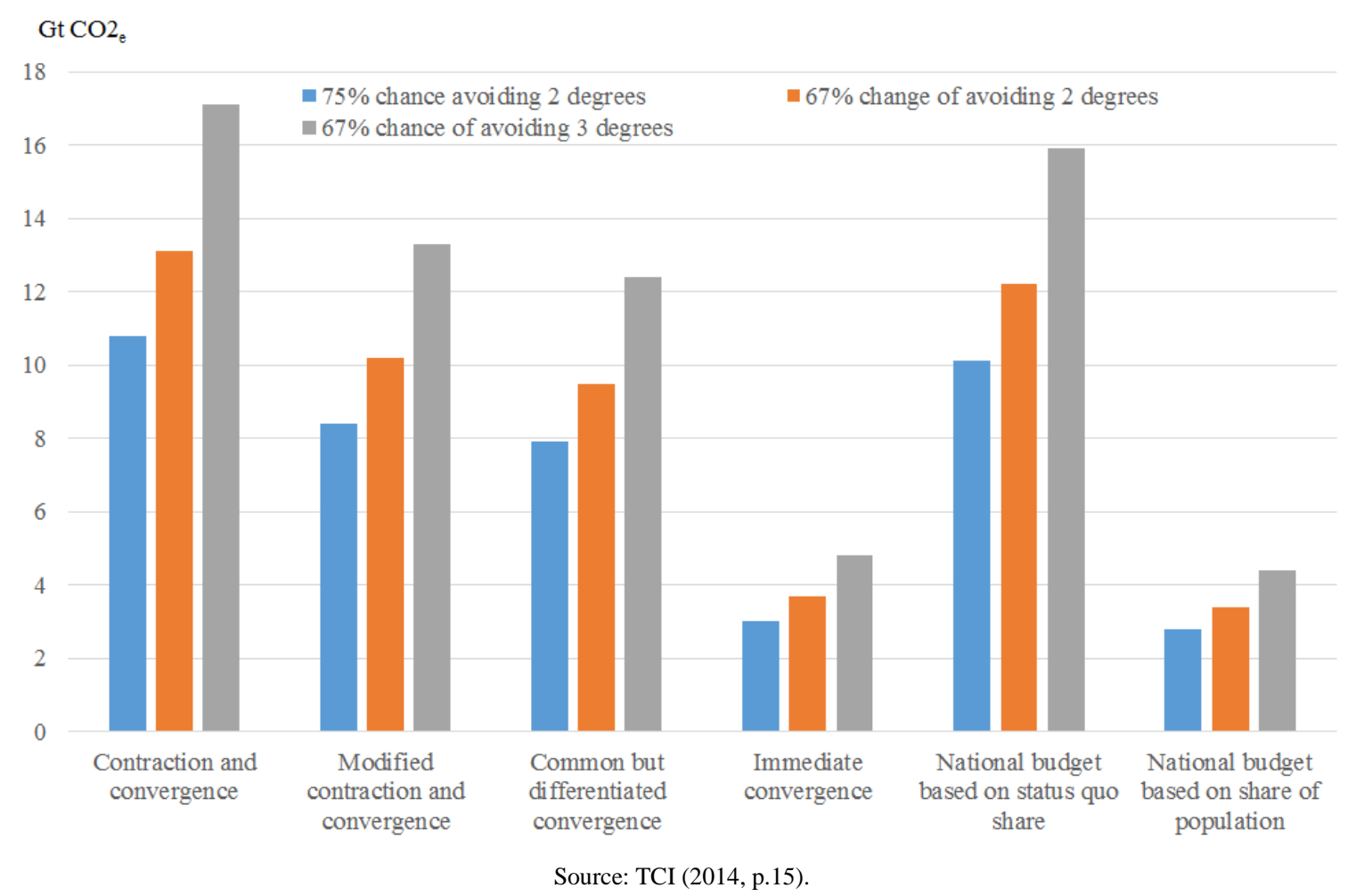

Based upon 2013/14 emissions of 542.6 million tonnes (Mt), Australia's 10 Gt 'carbon budget' presented in Figure 1 would be depleted by around 2033. If the budget was exhausted more gradually but at a fixed reduction rate, Australia would be required to reduce its emissions by $4 \%$ per annum to 2050. Achieving such a reduction is unlikely under 'business-as-usual' activities. Australian GHG emissions have fallen by around 1\% per annum over the past two years despite emissions in the electricity sector falling by approximately $20 \mathrm{Mt}$ or 10\% (Department of Environment, 2014). 
Table 1: Sectoral emissions in Australia

\begin{tabular}{cccc}
\hline Sector & Emissions (Mt) & \% of Australian total & \% change since 2003/04 \\
\hline Electricity & 179.4 & 33.1 & -7.8 \\
Non-elec stationary energy & 93.1 & 17.2 & 21.4 \\
Transport & 92.1 & 17.0 & 14.8 \\
Fugitive emissions & 45.2 & 8.3 & 20.2 \\
Industrial processes & 31.7 & 5.8 & -3.1 \\
Agriculture & 87.9 & 16.2 & -1.8 \\
Waste & 13.2 & 2.4 & -17.5 \\
\hline
\end{tabular}

Australia's sectoral emissions are presented in Table 1. The electricity sector comprises around one-third of Australia's emissions with other stationary energy and transport comprising another third. Electricity sector emissions have fallen markedly in recent years as a result of falling electricity demand and an increased proportion of gas-fired and renewable generation. On the other hand, non-electricity stationary energy and transport emissions have increased significantly, mostly due to the substantial growth in the resources sector.

Figure 2: Sectoral trends in Australian GHG emissions

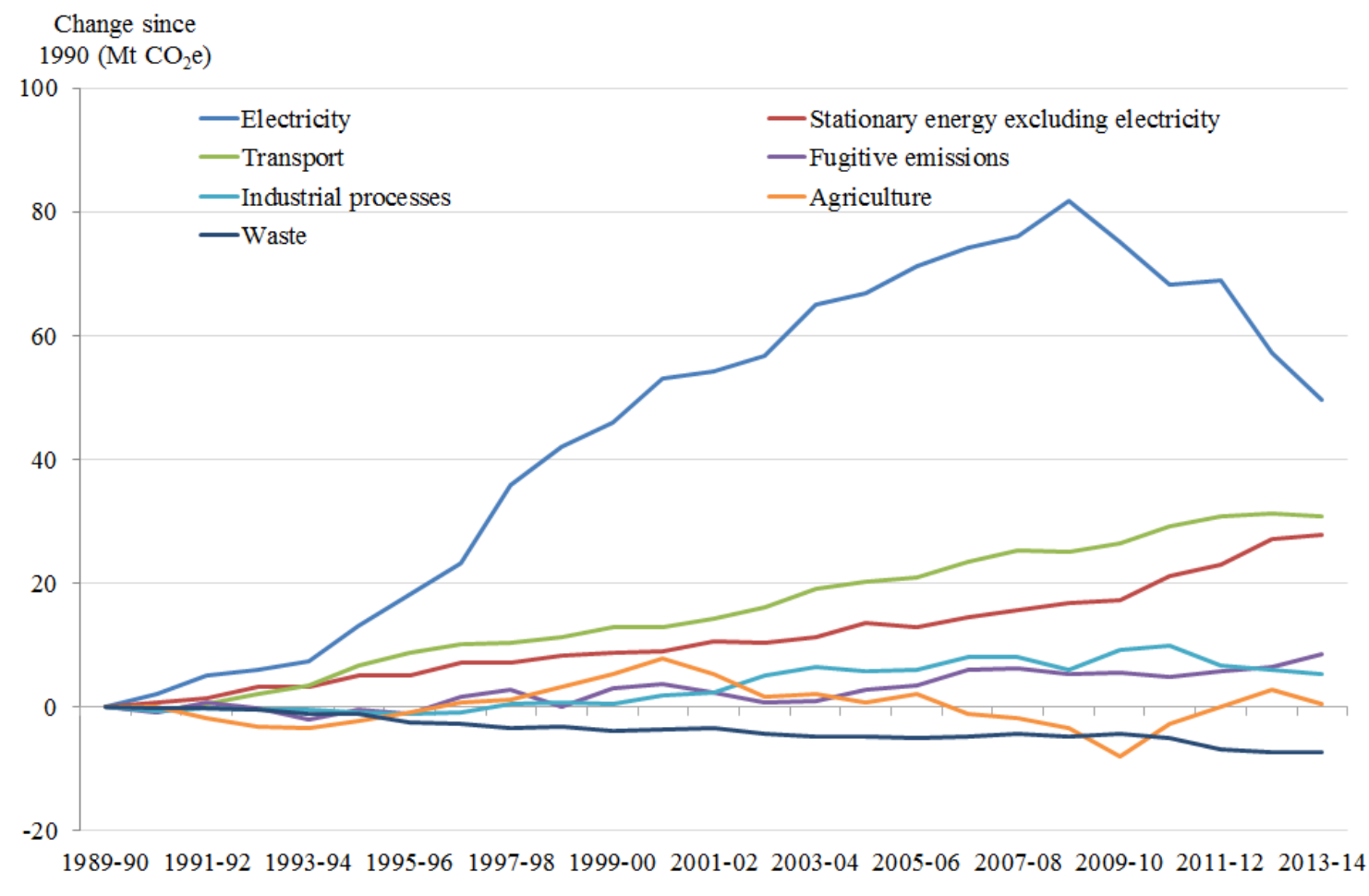

Source: Department of Environment (2014)

A longer-term trend of sectoral emissions is presented in Figure 2. Interestingly, the decline in electricity sector emissions is relatively recent with quite rapid growth in emissions occurring from 1990 to 2007. Emission reductions since 2007 partially reflect the availability of substitutes for existing relatively high emitting power generation sources and the use of policies such as Feed-in Tariffs, the QLD 13\% Gas Scheme and the 20\% Renewable Energy Target to encourage their deployment. A gas-fired combined cycle gas turbine (CCGT) produces between one-third to one-half of the emissions of existing conventional coal-fired power stations. Renewable generation such as large-scale wind and solar or small-scale solar produce zero GHG emissions. 
Gradual implementation of the $10 \mathrm{Gt}$ 'carbon budget' identified earlier in this Section would require emissions to be approximately $45 \%$ lower by 2030 . This is similar to the target modelled by Adams, Parmenter and Verikios (2014). Their study provides useful modelling insights into the economics of reducing emissions within Australia based upon the application of a 'global' emissions trading scheme. They find that application of a global GHG permit price results in half of all required Australian GHG abatement occurring outside Australia. This has important implications for policy which are discussed in the two subsequent sections. The modelling also shows the reduction in GDP associated with a $40 \%$ reduction in emissions by 2030 is just $1.1 \%$, relative to a 'business-as-usual' scenario. However, the impacts on specific sectors are wildly divergent. For example, electricity generation from gas increases by around $16 \%$ while coal mining output falls by around $13 \%$.

\section{Brief overview of climate change policies of sovereign nations}

Achieving global emission reductions identified as necessary by the IPCC is likely to be politically challenging. In 2010, 81\% of primary energy demand and 67\% of electricity production was sourced from GHG emitting energy sources - primarily coal, gas and oil (IEA, 2014). Eliminating emissions from energy production and consumption will require effective economic incentives to substitute towards lower emitting fuels or deployment of technologies that eliminate GHG emissions. The IPCC (2014, p.66) found that not deploying carbon capture and storage (CCS) technologies would increase the cost of GHG mitigation to achieve a $450 \mathrm{ppm}$ goal by $138 \%$ between 2015 and 2100. Despite this finding by the IPCC, much of the policy framework globally is aimed at incentivising renewable energy rather than 'zero-emission' energy resources. REN21 (2014, p. 77) estimates that there are 144 countries with renewable energy targets in place.

\subsection{Australian climate change policy}

Australian climate change policy to date could best be described as erratic and unfocused on any particular public policy objective. Simshauser (2014) has stated that Australia could be said to have undergone a 'policy-induced energy market death spiral'. Since 2010, emissions trading and premium feed-in tariffs (FiT) have both been introduced and abandoned while an expanded 20\% Renewable Energy Target has been introduced and subsequently split into a Small Scale Renewable Energy Scheme (SRES) and Large Scale Renewable Energy Target (LRET). At the time of writing, there is material policy uncertainty in relation to the LRET with the Commonwealth Government supporting a reduction of the fixed 41 TWh target to a 'real 20\%' target of approximately $30 \mathrm{TWh}$ by $2020 .^{1}$ There is no price mechanism in place for internalising GHG emission externalities and no GHG emissions performance standards in place for new power station developments. However, a Direct Action policy has been introduced which incorporates an auction process to allocate $\$ 2.5$ billion for emission reduction projects and a yet to be developed baseline setting process for major emitting facilities.

\subsection{European Union (EU) climate change policy}

The EU has committed to a 20\% reduction in emissions compared to 1990 levels by 2020, at least $40 \%$ by 2030 and $80-95 \%$ by 2050 . The policy mechanisms in place to achieve this mitigation target include: the EU Emissions Trading Scheme (ETS); regulations to reduce the emissions intensities of vehicles; feed-in tariffs for small-scale renewable energy; and various national measures to encourage large scale renewables and carbon capture and storage including market

\footnotetext{
${ }^{1}$ Despite legislative certainty being a commitment of major political parties in June 2015, the incumbent Government has described wind turbines as 'visually offensive' and indicated that it would have preferred to have implemented an even greater reduction in the target.
} 
based schemes, reverse auctions and feed-in tariffs. The EU ETS was initiated in 2005 and is now in its third phase. It covers 45\% of the EU's GHG emissions and places a cap on 11,000 large emitting industrial facilities such as power generators. These facilities are able to trade permits purchased from the EU - functionality that has established an European Emissions Allowance (EUA) spot price and associated derivative financial markets. The cap under the scheme is $21 \%$ lower in 2020 than in 2005.

\subsection{China's climate change policy}

China's $12^{\text {th }}$ Five Year Plan outlines a series of commitments including: a $16 \%$ reduction in energy intensity (energy consumption per unit of GDP); increasing non-fossil energy to $11.4 \%$ of total energy use; and a 17\% reduction in carbon intensity (carbon emissions per unit of GDP). The policy framework underpinning these commitments reflects that, 'climate policy goes hand in hand with other Chinese policy objectives, in particular reducing local air pollution' (Jotzo and Loschel, 2014, p. 3). In relation to renewable energy, China has policies in place to incentivise significant new additions of renewable capacity - $18 \mathrm{GW}$ of wind and 35GW of solar, including 20 GW of distributed solar PV. (REN21, 2014, p. 76). Of particular note is the development of seven regional pilot emissions trading schemes (ETS) covering 260 million people. The Chinese Government has also announced that a national ETS will be implemented before 2020. Jotzo and Loschel (2014, p.4) state that this is a significant development as, 'until recently, the Chinese climate policy repertoire consisted almost exclusively of regulatory interventions, as well as statedirected investment'.

\subsection{North American climate change policy}

In the US, regulatory efforts to limit GHG emissions have occurred at both the national and state level but largely do not involve the use of emissions trading. Many states have introduced renewable energy portfolio standards (see Sioshansi, 2014). The Federal Government has established a Climate Action Plan underpinned by the Clean Air Act. The US Environmental Protection Agency (EPA) has established a pair of rules under the legislation. The first rule is aimed at limiting GHG emissions from new electricity generation facilities. New performance standards (NSPS) establish separate GHG limits on new coal and gas generators. Coal plants will be required to meet a 12-month rolling average of 0.5 tonnes per MWh. Gas-fired generation facilities will be required to meet a limit of between 0.45-0.5 tonnes per MWh depending upon their technical characteristics (Mettler-LaFeir and Paul, 2014). In effect, such limits will prevent the construction of conventional coal-fired power stations which operate with best practice emissions intensities of closer to 0.7 tonnes per MWh (BREEb, 2012). However, new natural gasfired facilities will readily comply with the new obligations.

The second rule is outlined in the EPA's publication Carbon Pollution Emission Guidelines for Existing Stationary Sources: Electric Utility Generating Units which establishes state specific GHG emission goals. Individual states are able to meet their own goals using a range of measures and have until 2016 (with the possibility of a two year extension) of developing a viable plan. Based upon an assessment of these new regulations, Mettler-LaFeir and Paul (2014, p.21) state: 'The result, given the inherent constraints on nuclear and renewables and EPA constraints on coal, is that all paths lead to natural gas.' Since 2000, US electricity generation sourced from coal has declined from $52 \%$ to $41 \%$ and is projected by the EPA to fall to $30 \%$ by 2030 .

In Canada, measures have been introduced through the Reduction of Carbon Dioxide Emissions from Coal-Fired Generation of Electricity Regulations to force the retirement of power stations that are greater than 50 years old or require their retrofitting with CCS technology that achieves an emissions profile of around 0.4 tonnes per MWh - equivalent to a CCGT (Global CCS 
Institute, 2014, p. 73). The new rule is to apply from 1 July 2015 although temporary exemptions are available for plants that actively commence deployment of CCS technologies of some type.

\section{Insights relevant for Australian climate change policy}

The two major issues requiring resolution in Australia relate to: long and short-term policy objectives for domestic GHG emission reductions; and whether a 'regulatory' approach such as that being adopted by North America is preferential to a 'market-based approach' which has been adopted in the EU through its ETS and has been partially developed and fully committed to by China. Furthermore, as noted earlier in this article, Australia would be well placed to consider these issues not just as a 'direct emitter' of GHG emissions but also as a significant exporter of emitting fuels that will be required to participate in global negotiations about emission reduction targets and policies.

It is probable that recent US climate change policy developments have been partially facilitated by new opportunities for reducing emissions - significant volumes of unconventional gas developed through new innovative horizontal drilling and other new technologies. Between 2003 and 2013, proven reserves of natural gas in the US almost doubled from 5.4 trillion cubic metres to 9.3 trillion cubic metres (BP, 2014, p. 20). The price of gas (wholesale Henry Hub pricing) in the US has fallen by two thirds since 2008. Accordingly, the regulatory standards introduced by the US Federal Government could be said to be 'making hay while the sun shines' as the increased use of gas-fired generation (at the expense of coal) was already well underway due to the relative economics of the fuels. This is further supported by analysis which shows that $15 \%$ of the existing coal-fired generation fleet has either been retired or is slated for retirement in the near future (Fleischman et al, 2014, p.51). However, irrespective of their causal origin, regulatory standards (as opposed to international market based measures) ensure that the abatement of GHG objective is delivered through domestic economic activity.

As a contrast to the current regulatory approach adopted by the US, CGE modelling provides significant insight into the economic outcomes associated with emissions trading policies with international linkages (such as the EU ETS). Adams et al (2014) outline a series of key insights based upon their CGE modelling of emissions trading within Australia. Importantly, they find that the application of global carbon pricing would see only half of the GHG abatement achieved being sourced from within Australia. This can be viewed in two distinct ways: international abatement is cheaper and therefore a sensible way in which to minimise costs to Australia; or decarbonisation of Australia's economy is 'deferred' thus exposing Australia to greater structural shocks in the future should 'deep cuts' be required domestically. This has important policy implications. If the goal of Australian policy makers is to reduce emissions at lowest possible cost, then relatively inexpensive international abatement should be facilitated. However, inclusion of international abatement effectively reduces the structural reform of the Australian economy and does very little to address the strategic risks to Australia's exports of coal and gas.

\subsection{The impact of gas prices, declining demand and barriers to exit on electricity sector emissions mitigation}

Australia needs to consider the contrast between domestic gas supply/demand dynamics and those in the US. Australia has seen a similar 'gas revolution' as in the US but the outcomes domestically could not be more different. In the US, gas prices have fallen by around two-thirds due to restrictions on increased gas supplies being exported as LNG. In Australia, gas prices are expected to rise due to unprecedented increases in east-coast demand associated with the development of an east-coast LNG export industry. These issues are well documented in Simshauser and Nelson (2015a), Grafton and Lambie (2014) and Simshauser and Nelson (2015b). The opportunities for Australia to introduce either a market-based or regulatory policy designed 
to incentivise the deployment of new CCGT (as is happening in the US) to displace new coal investment will be hampered by cost. High gas costs will cause higher electricity prices if gas is to be utilised as a 'transitional fuel'.

Figure 3: Costs of different generating technologies
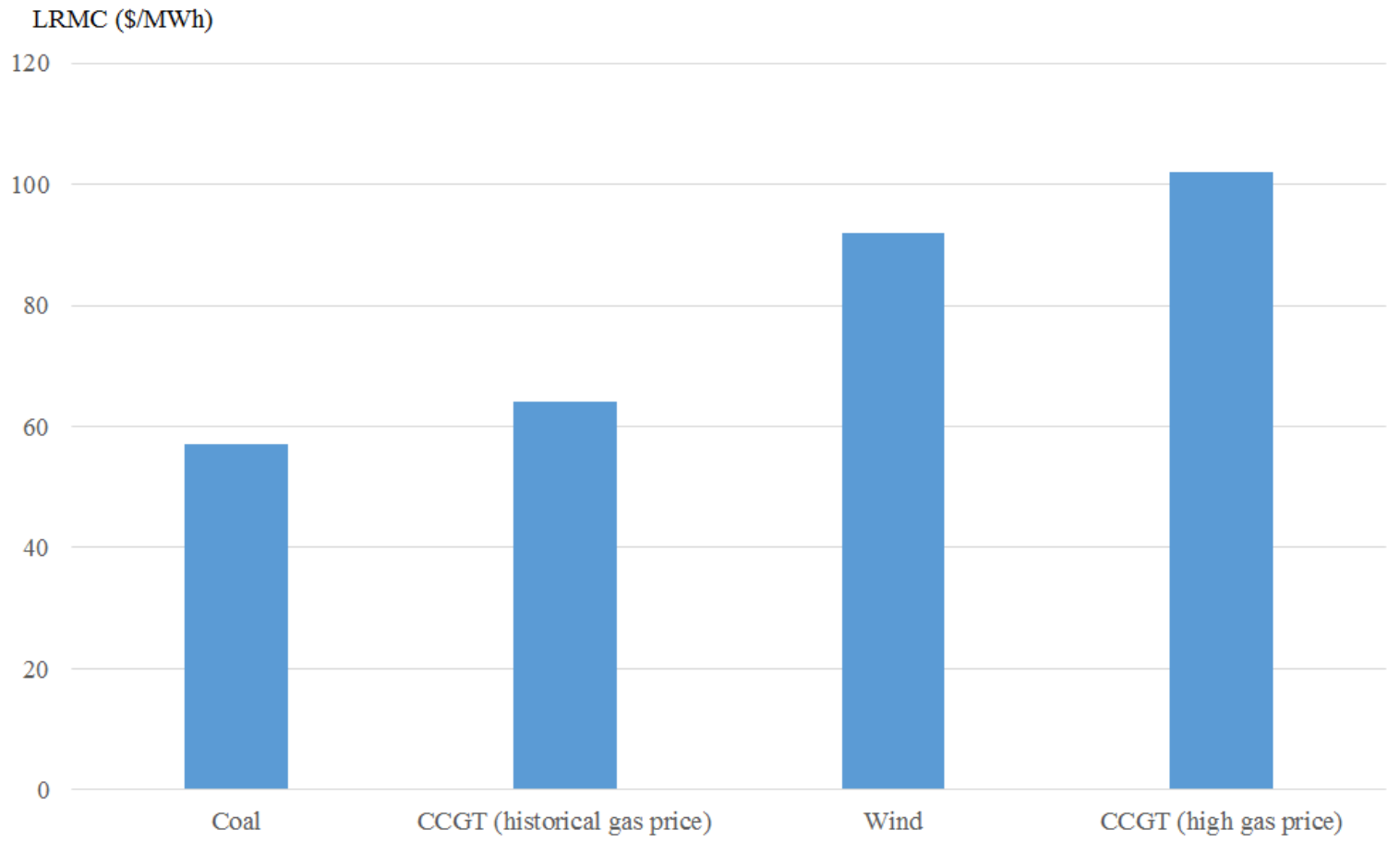

Source: Adapted from Nelson et al (2013) and Simshauser and Ariyaratnam (2014)

The long-run marginal cost of alternative generating technologies is presented in Figure 3. The current tight gas supply/demand balance outlined in Simshauser and Nelson (2015a) translates into gas-fired generation costs higher than alternative low emission technologies such as wind. It is beyond the scope of this article to determine whether the current tightness in the domestic gas market will persist. The gas industry has significant issues associated with its 'social licence to operate' as Simshauser and Nelson (2014b) articulate. Even if new gas exploration activity were undertaken in the next few years, it would take some time for sufficient supply to enter the market and impact on domestic gas prices significantly (see ACIL Allen, 2014). And even with new gas supplies in place, it would take another several years for new gas-fired power stations to be permitted and constructed. It is therefore reasonable to conclude that carbon prices in Australia would need to be materially higher than the previous price of \$23/tonne for new gas-fired electricity capacity to displace new coal-fired generation in the short to medium term. This is an important consideration for policy makers given gas has been thought of as a 'transitional fuel' over the past two decades.

Another changing dynamic in the Australian electricity market relates to declining electricity demand. In the 2000s, there was very little policy discussion about how emissions would be reduced if electricity demand did not grow - necessitating the structural substitution of existing high-emitting coal capacity with new low-emission generation. In the previous two decades to 2009, Australian electricity demand grew consistently. With this as a backdrop, emissions trading schemes were often assessed by the 'carbon price' required to effect the substitution of existing coal-fired generation with new gas-fired power plants (see Nelson et al, 2010 as an example). 
Figure 4: Carbon pricing and LRMC in a hypothetical two fuel system 


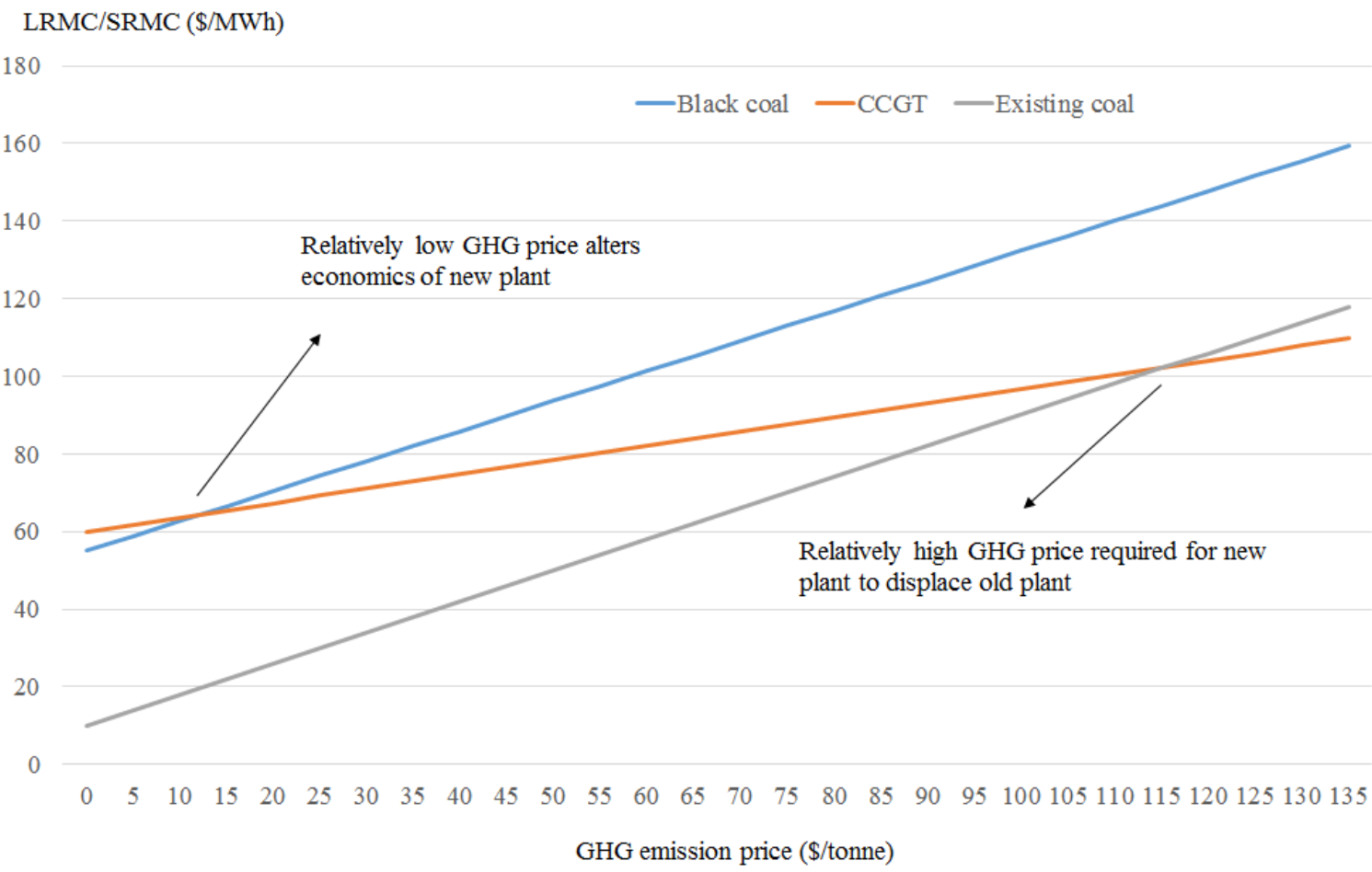

Source: Author calculations produced using costs and emissions estimated by Simshauser and Ariyaratnam (2014) and BREE (2012b).

Figure 4 shows that the carbon price required to effect fuel substitution is relatively low in a hypothetical electricity market with three technologies and historical gas and coal pricing. New CCGT plant (orange line) is a more economic investment than new coal (blue line) at a carbon price of around \$15/tonne. Based upon a 'pass-through' rate of the emissions intensity of average Australian electricity supply (see Nelson, Kelley and Orton, 2012 for an explanation of passthrough economics), such substitution would result in wholesale electricity prices increasing by around \$12/MWh - approximately a 3\% increase on a residential electricity bill.

Since 2009 however, electricity demand has fallen by around 5\% (see Saddler, 2013 for a good explanation of the drivers of this demand decline). There is a significant gap between the LongRun Marginal Cost (LRMC) of new generation technologies and the Short-Run Marginal Cost (SRMC) of existing generators where capital costs are sunk. In Figure 3, the carbon price required to effect the substitution of existing coal (grey line) with new CCGT (orange line) is around \$110/tonne. Such a carbon price is more than four times higher than the previous Australian fixed carbon price of around \$23/tonne and would result in electricity price uplifts of approximately $\$ 90 / \mathrm{MWh}$ - an increase of $30 \%$ on a residential bill.

An important question for policy makers is whether the current structural oversupply of Australian electricity markets will persist into the future or whether future demand growth will absorb the capacity with the reintroduction of greater levels of demand volatility, thereby increasing the attractiveness of investment in new (potentially lower emitting) power generation capacity. AEMO (2014) has estimated that even under the strongest demand growth scenario, there is still likely to be around 5,000 MW of surplus capacity on the Australian east-coast in 2023/24. Figure 5 shows the range of potential outcomes forecast by AEMO in its Statement of Opportunities, the annual system forecast of demand and supply. Within ten years, it is possible that oversupply of generation capacity could be as high as 12,000 MW.

Figure 5: Structural oversupply projections in the NEM by AEMO 


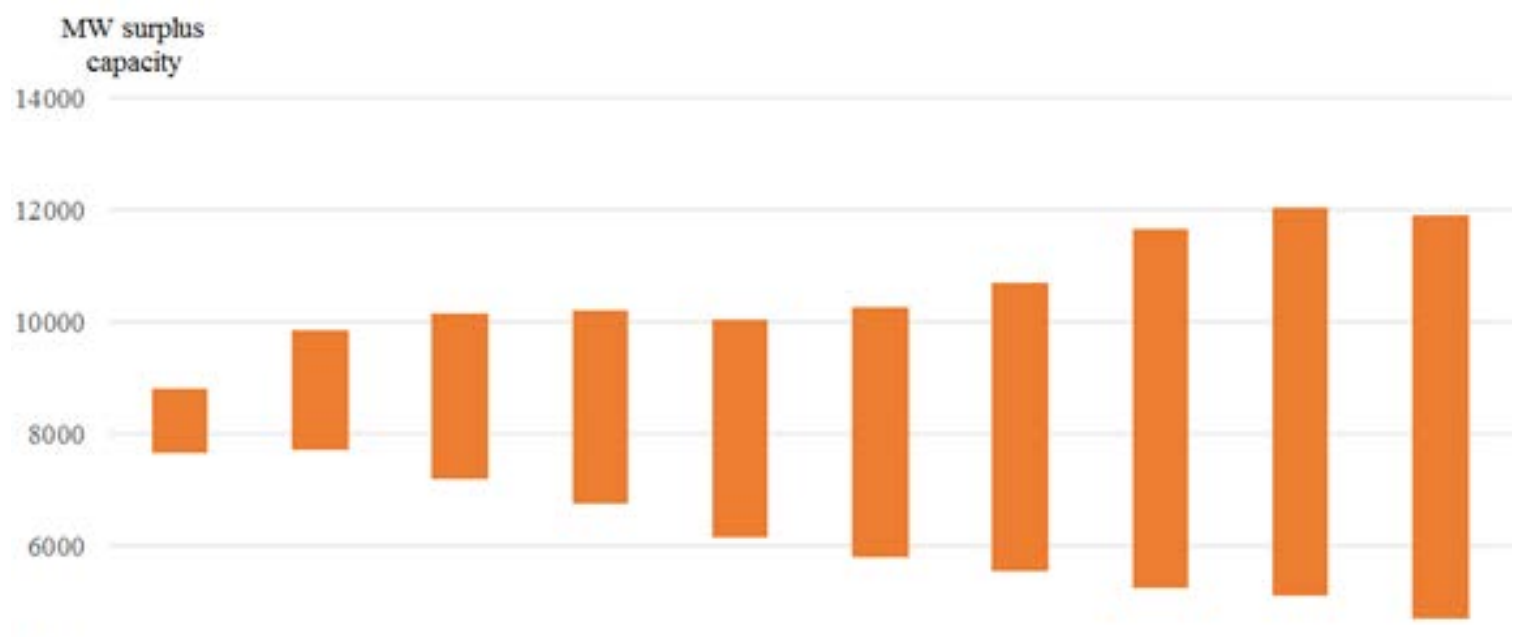

4000

2000

0

$2014-15 \quad 2015 \cdot 16 \quad 2016-17 \quad 2017 \cdot 18 \quad 2018 \cdot 19 \quad 2019 \cdot 20 \quad 2020-21 \quad 2021-22 \quad 2022 \cdot 23 \quad 2023 \cdot 24$

Source: AEMO (2014)

In a growing demand environment, regulatory and market-based climate policies could both ignore a structural new plant LRMC/existing plant SRMC cost gap phenomenon to some extent, at least temporarily. It was implicitly assumed that new lower-emitting infrastructure would be installed to meet growing demand and to replace the orderly retirement of high emitting end-oflife assets. However, 'beyond design life' asset operators have been reluctant to close such generators, instead preferring to mothball their plant. Barriers to exit and an ageing power station fleet are another key consideration for policy makers. Around $75 \%$ of the existing thermal plants have passed their useful engineering life. More importantly, ca.20\% is more than 40 years old (Nelson, Reid and McNeill, 2015). ${ }^{2}$

Nelson, Reid and McNeill (2015) provide a detailed explanation of barriers to exit for incumbent power stations. The first two barriers to exit relate to deferral of site remediation costs (with mothballing a preferred option instead); and asset sweating. They also find that it is likely that the effects of policy uncertainty, readily identified as having created sub-optimal new capital stock investment and as summarised in Nelson et al (2012), is no doubt creating sub-optimal decision making in relation to capital stock retirement. Their study estimates that there is currently around 7,000 MW of surplus to requirement plant within the NEM. Irrespective of the debate about carbon pricing, they state:

“..that investment in an optimal plant mix and associated ongoing reliability is likely to be problematic in the NEM in the long-run. This is because demand has been contracting while new renewables continue to be added to the aggregate supply function which is exacerbating an already oversupplied market. Aged incumbent steam plants continue to be available for dispatch or mothballed rather than permanently retired. Given demand forecasts are being continually revised down, closure of existing plants seems to be a crucially important step for overcoming the intractability of new renewable investment."

\footnotetext{
2 The ageing of plant is an important policy consideration. While climate policy will seek to reduce emissions at lowest cost, it is also important that an orderly replacement of the capital stock occur to ensure reliability is not put at risk in the market for electricity - an 'essential service'.
} 
The analysis in this section has shown that relatively high carbon prices would be required to effect substitution of existing coal-fired generation capacity with new gas-fired electricity infrastructure. This is due to both higher gas prices on the Australian east-coast and declining electricity demand necessitating capital stock replacement (rather than addition). Furthermore, there is emerging evidence that barriers to exit for incumbent power stations may need to be overcome irrespective of electricity demand growth or decline. While this analysis has been confined to the electricity sector, recall from Section 2 that power generation comprises around one-third, and stationary energy approximately half, of Australian emissions respectively.

\subsection{Utilising domestic climate change policy in strategic international negotiations}

While carbon pricing is likely to be difficult to implement due to both political opposition and the effects of higher gas prices and declining demand, other regulatory and legislative instruments are in place which have the effect of reducing emissions. The most prominent of these is the LargeScale Renewable Energy Target (LRET). Globally, such a policy is well founded - with 144 countries having support mechanisms for renewables of some type. Much of the public discussion in Australia has been based on the level of the target in 2020 - specifically, whether the target should be a fixed $41 \mathrm{TWh}$, a lower fixed amount, or a relative and floating target such as a 'real 20\%'. Such discussion ignores three fundamental policy questions: will investment be forthcoming at any level given the barriers to exit for incumbent plant?; is the mandated LRET (high capital cost technology) compatible with the east-coast National Electricity Market's energy-only design (covering only running costs - see Nelson, Reid and McNeill 2015)?; and should the LRET be expanded to include all 'zero emission technologies'? ${ }^{3}$

Regarding the third question, it may be in Australia's strategic interests to expand the LRET to include projects utilising coal and gas that achieve zero or negligible emissions. As a major exporter of coal and gas, Australia's export revenues could be significantly curtailed should new CCS-style technology not be developed and made cost-effective within a '450 ppm' decarbonised world. As Australia currently derives $26 \%$ of its export goods revenues from coal and other mineral fuels, the nation is vulnerable to any global technological change which results in the substitution of existing fuels for electricity and energy production. Importantly, CCS-technologies would not be given a 'free-ride' but would be required to compete with renewable sources to achieve the overarching policy objective required to meet a $10 \mathrm{Gt}$ carbon budget: the development and deployment of energy production technologies that produce zero emissions.

\footnotetext{
${ }^{3}$ A more fundamental point is whether the LRET policy is economically justified in the first instance. Arguments have been made against tradeable certificate schemes. Woodman and Mitchell (2011) summarise many of these points well. Given the policy is already in existence, this article assumes its continued operation given widespread public support. For example, a February 2014 poll found that 64\% of Australians believe the existing 20\% RET is either 'too low' or 'about right'. 23\% 'don't know' about the target and 13\% believe it is 'too high'. See http://essentialvision.com.au/renewable-energy-target-2, Accessed online on 8 June 2015.
} 
Figure 6: Large CCS projects by lifecycle stage and region

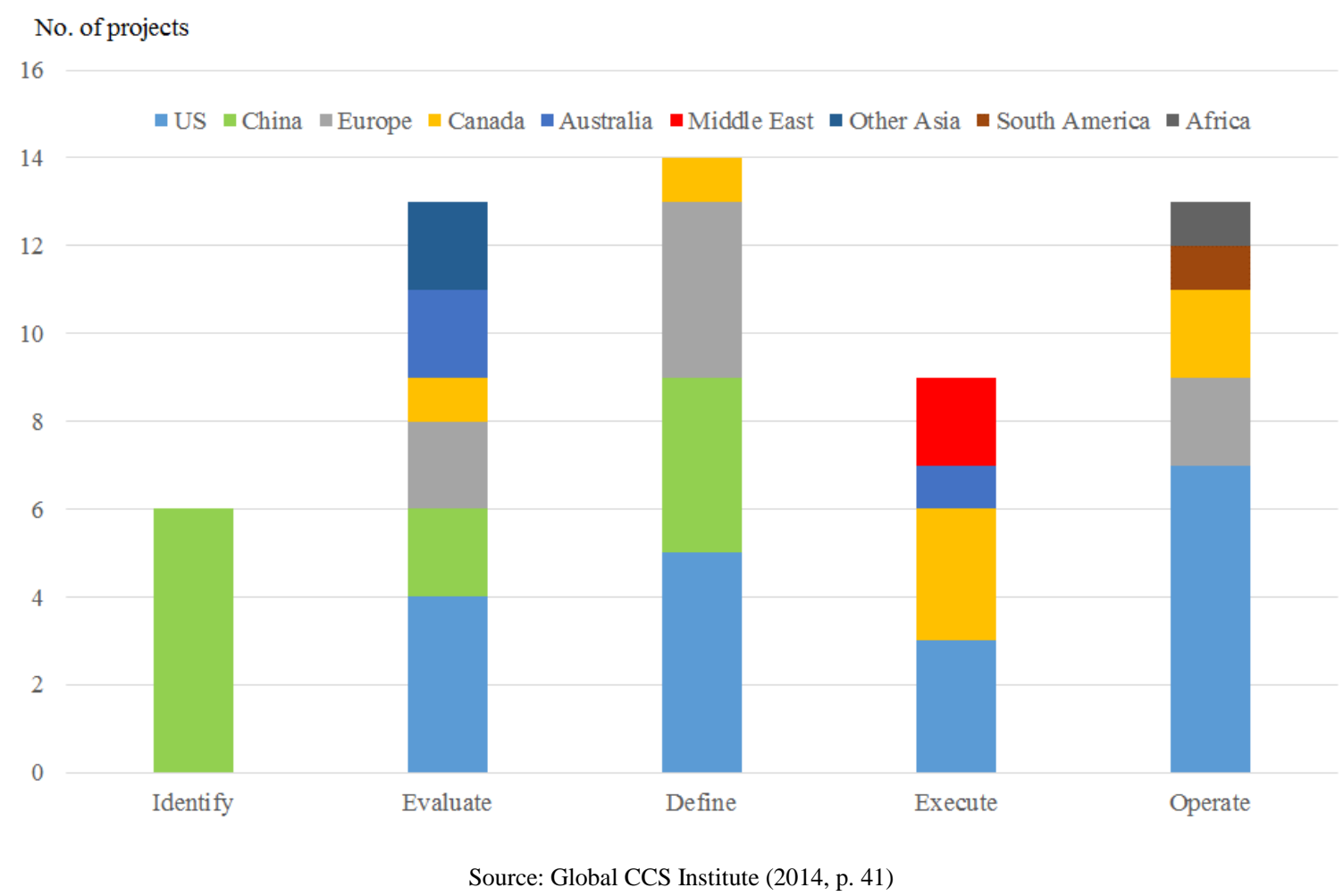

Figure 6 shows the number of large-scale CCS projects at various lifecycle stages. There are 13 projects operating in the US, Europe, Canada, South America and Africa. For a country with significant fossil fuel reserves and economic export exposure to reduced international demand for coal and gas, it is puzzling that Australia has only 1 CCS project being executed at the time of writing (Global CCS Institute, 2014, p. 41). As one of the largest energy exporters in the world, with most energy revenue coming from fossil fuels, it is almost indisputable that the development of CCS technology is likely to be in Australia's strategic interests.

As identified in Section 2, achievement of $450 \mathrm{ppm}$ as a global climate change policy goal requires the decarbonisation of energy supplies in the long-term. In such an environment, coal and gas are directly competing with new technologies such as solar and wind and existing zero emission technologies such as nuclear. Australian policy should explicitly recognise this. Such recognition would be based upon scientific opinion - as noted earlier, the IPCC has stated that decarbonisation without CCS technology may result in global mitigation costs $138 \%$ higher than necessary (IPCC, 2014). Furthermore, based upon current technological assessments, it is likely that CCS will be required for some industrial processes irrespective of whether or not it is successfully used in the electricity generation sector. The European Union (2014) for example, has stated, 'As theoretical limits of efficiency are being reached and process-related emissions are unavoidable in some sectors, CCS may be the only option available to reduce direct emissions from industrial processes on the scale needed in the longer term.'

Importantly, Australia could advocate for other nations to adopt such a policy through international negotiations such as COP21 in Paris in December 2015. This would be an important development for several reasons. Firstly, it may be seen as a constructive act of diplomacy from a country that has been described as a 'free rider' on climate change mitigation policy ${ }^{4}$. Secondly, it

\footnotetext{
${ }^{4}$ See www.bbc.com/news/world-australia-33017594 for further discussion on United Nations commentary on Australia's approach to climate change treaty negotiations.
} 
would be useful for securing support for international engagement from Australia's coal and gas industries. Australia's coal industry has at times been accused of being less than constructive in engaging on the issue of climate change. By explicitly allowing for the development of new technologies utilising coal and gas, it would be difficult for these industries not to support such an expansion of existing policy. Also, such a policy is likely to be actively supported by investors concerned about the growing 'divestment' movement within financial markets (see Ansar et al, 2013).

Finally, without other nations adopting similar policies, an Australian 'zero emissions' target through an expansion of the LRET is unlikely to significantly spur much in the way of new investment. Large electricity generation manufacturers (e.g. General Electric, Vestas, and Siemens etc) cannot develop economies of scale for new technologies with only the Australian market for deployment due to its relatively small size. However, if other nations adopted similar 'zero emissions' targets by expanding their renewable schemes' eligibility, there would be a sizeable global market for CCS and other 'zero emission' technologies. As such, by linking Australian domestic policy with international climate change negotiations, the Australian Government could seek to secure international support for the development of industries that may ${ }^{5}$ support the ongoing viability of Australian gas and coal exporters in a carbon constrained future.

Domestically, there is precedent for considering the expansion of renewable policy to include all 'zero emission' sources of energy. In 2007, the incumbent Commonwealth Government proposed to expand the existing Mandatory Renewable Energy Target (MRET) to $30 \mathrm{TWh}$ and include 'zero emission' sources such as CCS to compete with already eligible renewable energy sources. At the time, the Renewable Energy Generators of Australia (REGA) peak renewable energy industry body tentatively supported the proposal and stated, 'You need to get investment into the areas where the best resources are available' (ABC, 2007). The policy was not adopted by the subsequent Commonwealth Government with the expanded 41 TWh renewable target instituted instead.

To reduce current oversupply and facilitate new investment in either renewables or other 'zero emission technologies', Australian policy makers may wish to consider ways in which to incentivise the closure of existing power stations and encourage 'zero emission technologies ${ }^{6}$. Nelson, Reid and McNeill (2015) outline three basic approaches for such policy: government funding; a market-based mechanism; or direct regulation. Interestingly, this would not be without precedent as noted in the previous section of this article. Canada has instituted policies directly aimed at overcoming barriers to exit of older high-emitting power assets. A regulatory framework could be developed that allows older power stations to be progressively either: closed (and replaced with a lower emitting capital stock); or retrofitted with carbon capture and storage (CCS). Such a policy, if sufficiently telegraphed to investors, could be complementary to both a regulatory approach (as in the US) and a market-based approach (as in the EU ETS or the current baseline and credit Direct Action Australian policy). ${ }^{7}$

\section{Concluding remarks}

It is beyond the scope of this article to state definitively state whether a market-based mechanism is a superior policy approach to direct regulation. Different countries have pursued both and

\footnotetext{
${ }^{5}$ Depending upon whether the CCS style technology can compete with substitutes (e.g. wind, solar, nuclear).

${ }^{6}$ Without facilitated closure, Nelson, Reid and McNeill (2015) argue that new investment will be increasingly reliant upon revenue from subsidies rather than wholesale electricity market revenue. They argue that this is unlikely to be supported by investors.

${ }^{7}$ A facilitated closure policy would be useful in preventing firms from spending funds on capital investment in maintenance and refurbishment of assets that are inconsistent with requisite climate change mitigation.
} 
argued their superiority to each other. Freebairn (2014) and Garnaut (2014) summarise theory and policy well in discussing the arguments for and against market pricing or subsidies as policy tools for achieving GHG mitigation. Freebairn (2014) notes, 'the price strategy will have a larger effective base, and lower transaction costs which, together, lead to lower costs per unit GHG reduction' (Freebairn, 2014, p. 241). While economic theory states that the market will deliver a lowest cost option, the interaction between Australia's economy and a global 'carbon market' as well as the interplay between electricity and gas markets with GHG pricing, complicates the situation for policy makers.

The insights in this article provide some policy direction, depending upon the overarching objective to be pursued. Australia is a small overall emitter and therefore extremely likely to be a 'price taker' in an international emissions trading environment. If the objective of policy is to structurally decarbonise the Australian economy, GHG pricing may not result in GHG mitigation in Australia - a point noted in Adams et al (2014). It may also do nothing to address the risks to Australian energy exports in a ' 450 ppm world' where significant efforts are being made to develop substitutes for coal and gas. Furthermore, the incentive to substitute existing high emitting but 'sunk' capital cost facilities with new low emissions investments requires a relatively high carbon price in a 'cap and trade' framework given higher gas prices and declining electricity demand necessitating substitution of incumbent infrastructure. Such a high carbon price would be transmitted through the economy and may result in higher economic distortions than necessary, if alternative policies were adopted. While a baseline and credit scheme may overcome some of these issues, it would not overcome the 'poisonous politics' associated with carbon pricing as a policy issue.

Strategically, Australia needs to consider how it will constructively work towards its commitment to participate in international negotiations aimed at limiting climate change to $2^{0} \mathrm{C}$ - particularly in the lead up to COP21 in Paris in December 2015. The electricity industry provides some interesting options for Australian policy given it is Australia's highest emitting sector. In North America, policy-makers have recognised that the sector is comprised of a relatively small number of directly-emitting facilities and embraced regulation as the means by which to reduce GHG emissions. In Australia, the vast majority of electricity GHG emissions are produced by less than 30 large coal-fired power stations. In the absence of any bipartisan agreement on whether to introduce an economy-wide GHG price or utilise a regulatory approach, mitigation in the electricity sector could be relatively easily addressed through: amendments to the existing LRET to include all 'zero emission' energy sources; new standards for power stations (as implemented in the US) ${ }^{8}$; and regulations for incumbent plant retirement (as proposed in Canada). This article does not support such measures without qualification - economic modelling would be required to determine the impact of such approaches. However, such policy would address a glaring omission: strategic consideration of Australia's role as an energy exporter, through the inclusion of CCS and other zero emission technologies within Australia’s policy framework. This would provide an important example of constructive policy which Australia could seek to see replicated in other countries through advocacy within international climate change negotiations.

\footnotetext{
${ }^{8}$ The International Energy Agency (IEA) has placed major emphasis on the urgency of strong mitigating action with respect to carbon emissions and one reason the IEA gives for this is the need to preclude the 'lock in' of new investment in coal-fired electricity generation.
} 


\section{References}

ACIL Allen. (2014), 'Future NSW gas supply and useage', A report to AGL Energy by ACIL Allen, Accessed online at http://aglblog.com.au/wp-content/uploads/2014/07/Final-ACIL-AllenReport-July-2014.pdf on 8 June 2015.

Adams, P., Parmenter, B. and Verikios, G. (2014), 'An Emissions Trading Scheme for Australia: National and Regional Impacts’, Economic Record, Vol. 90, No. 290, pp. 316-344.

Ansar, A. Caldecott, B. and Tilbury, J. (2013), 'Stranded assets and the fossil fuel divestment campaign: what does divestment mean for the valuation of fossil fuel assets?', Smith School for Enterprise and the Environment Paper, Oxford.

Australian Broadcasting Corporation: ABC (2014), China and US agree on ambitious greenhouse gas emissions targets, Accessed online at http://www.abc.net.au/news/2014-1112/china-and-us-agree-on-ambitous-gas-emissions-targets/5886200 on 12 January 2015.

Australian Broadcasting Corporation: ABC (2007), PM announces national clean energy target, Accessed online at http://www.abc.net.au/news/2007-09-23/pm-announces-national-cleanenergy-target/677918 on 12 January 2015.

Australian Bureau of Statistics: ABS. (2014), International Trade in Goods and Services, Australia, Nov 2014, Accessed online at http://www.abs.gov.au/AUSSTATS/abs@.nsf/DetailsPage/5368.0Nov\%202014?OpenDocument on 12 January 2015.

Australian Energy Market Operator: AEMO. (2014), 2014 Statement of Opportunities, AEMO Publication, Sydney.

BP. (2014), BP World Statistical Energy Review, BP Publication, London. 
Bureau of Resource and Energy Economics: BREE. (2012a), Energy in Australia 2012, BREE Publication, Canberra.

Bureau of Resource and Energy Economics: BREE. (2012b), Australian Energy Technology Assessment, BREE Publication, Canberra.

Department of Environment. (2014), Quarterly Update of Australia's National Greenhouse Gas Inventory: June 2014, Department of Environment Publication, Canberra.

Environment Protection Agency: EPA. (2014), Global Greenhouse Gas Emissions, Accessed online at http://www.epa.gov/climatechange/ghgemissions/global.html on 12 January 2015.

European Commission. (2013), Trends in Global GHG Emissions, European Commission Joint Research Centre, The Hague.

European Union: EU. (2014), Climate Action, Accessed online at http://ec.europa.eu/clima/policies/lowcarbon/ccs/index_en.htm on 12 January 2015.

Fleischman, L., Cleetus, R., Deyette, J., Clemmer, S. and Frenkel, S. (2014), 'Ripe for Retirement: An Economic Analysis of the U.S. Coal Fleet', The Electricity Journal, Vol. 26, No. 10, pp. 51-63.

Freebairn, J. (2014), 'Carbon Price versus Subsidies to Reduce Greenhouse Gas Emissions', Economic Papers, Vol. 33, No. 3, pp. 233-242.

Garnaut, R. (2014), 'Resolving Energy Policy Dilemmas in an Age of Carbon Constraints', The Australian Economic Review, Vol. 47, No. 4, pp. 492-508.

Global CCS Institute. (2014), The Global Status of CCS: 2014, Global CCS Institute Publication, Melbourne.

Grafton, Q. and Labmie, R. (2014), ‘Australia’s Liquefied Natural Gas Sector: Past Developments, Current Challenges and Ways Forward', The Australian Economic Review, Vol. 47, No. 4, pp. 509-22.

Intergovernmental Panel on Climate Change: IPCC. (2014), Climate Change 2014 Synthesis Report of the Fifth Assessment: Summary for Policymakers, IPCC Publication.

International Energy Agency: IEA. (2014), IEA World Energy Outlook, IEA Publication, Paris.

Jotzo. F. and Loschel, A. (2014), 'Emissions trading in China: Emerging experiences and International lessons’, Energy Policy, Vol. 75, pp. 3-8.

Mettler-LaFeir, D. and Paul, T. (2014), 'New EPA Carbon Rules Change Outlook for Future Mix of Fuels’, The Electricity Journal, Vol. 27, No. 6, pp. 17-25.

Nelson, T., Reid, C. and McNeill, J. (2015), 'Energy-only markets and renewable energy targets: complementary policy or policy collision’, Economic Analysis and Policy, Vol. 46, pp. 25-42.

Nelson, T., Orton, F. and Kelley, S. (2012), “A literature review of economic studies on carbon pricing and Australian wholesale electricity markets”, Energy Policy, Vol. 49, pp. 217-224. 
Nelson, T., Simshauser, P., Orton, F. and Kelley, S. (2012), "Delayed carbon policy certainty and electricity prices in Australia: A concise summary of subsequent research”, Economic Papers, Vol. 31, No.1, pp.132-135.

Nelson, T., Kelley, S., Orton, F. and Simshauser, P. (2010), "Delayed carbon policy certainty and electricity prices in Australia”, Economic Papers, Vol. 29, No. 4, pp. 446-465.

Renewable Energy Policy Network for the $21^{\text {st }}$ Century: REN 21. (2014), Renewables 2014: Global Status Report, REN21 Publication, Paris.

Saddler, H. (2013), 'Power Down: Why is electricity consumption decreasing', Australia Institute Paper, No. 14.

Simshauser, P. (2014), 'From first place to last: Australia’s policy-induced energy market death spiral’, The Australian Economic Review, Vol. 47, No. 4, pp. 540-62.

Simshauser, P. and Nelson, T. (2015a), 'Australia's coal seam gas boom and the LNG entry result', Australian Journal of Agricultural and Resource Economics, Vol. 59, pp. 122.

Simshauser, P. and Nelson, T. (2015b), 'The Australian east coast gas supply cliff'”, Economic Analysis and Policy, Vol. 45, pp. 69-88.

Simshauser, P., and Ariyaratnam, J. (2014), 'What is Normal Profit for power generation?', Journal of Financial Economic Policy, Vol. 6, No. 2.

Sioshansi, F. (2014), EEnergy Informer: The International Energy Newsletter, Vol.24, No.11, November.

The Climate Institute: TCI. (2014), Australia's Post-2020 Emission Challenge: Our role in the international cycle of growing ambition, The Climate Institute Publication, Sydney.

Woodman, B., and Mitchell, C. (2011), 'Learning from experience? The development of the Renewables Obligation in England and Wales 2002-2010', Energy Policy, Vol. 39, pp. 39143921. 